\title{
SISTEM INFORMASI AKUNTANSI SEBAGAI BAGIAN TATA KELOLA KEUANGAN UNTUK MEWUJUDKAN SMART CITY DI DKI JAKARTA
}

\author{
Dyah Puspitasari Sunaryo Putri \\ Dosen Fakultas Teknik Program Studi Teknik Industri, Universitas Pamulang \\ dyah.puspita80@gmail.com
}

\begin{abstract}
ABSTRAK
Smart city adalah konsep kota cerdas yang mengoptimalkan pemanfaatan Teknologi Informasi dan Komunikasi (ICT). Sistem informasi akuntansi merupakan bagian dari sistem informasi mempunyai peranan yang penting dalam smart city terutama tata kelola pemerintah. Dengan menggunakan metode kualitatif deskriptif, penelitian ini melihat teknologi dan teknik sistem informasi akuntansi pada smart city serta praktiknya di DKI Jakarta. Penelitian ini dapat disimpulkan bahwa pemerintah provinsi DKI sudah membuat langkah awal mengembangkan sistem informasi akuntansi dalam kerangka mewujudkan smart city.
\end{abstract}

Kata kunci : Smart City, Sistem Informasi Akuntansi, Tata Kelola.

\section{PENDAHULUAN}

Bentuk baru pembangunan yang berkelanjutan, konsep "smart city" telah menarik perhatian beberapa tahun ini. Definisi smart city sendiri beraneka ragam dan beberapa peneliti mendalami area ini. Caragliu et al (2011) menyakini bahwa sebuah kota akan menjadi smart ketika investasi modal manusia dan sosial memicu ekonomi yang berkelanjutan dan kualitas hidup tinggi, dengan pengelolaan yang bijak terhadap sumberdaya alam.

Pengembangan teknologi informasi dan komunikasi serta penerapan elektronifikasi merupakan aspek penting menuju penerapan konsep smart city yang nantinya diharapkan dapat memperbaiki pelayanan pemerintah kota untuk menghasilkan proses kerja yang lebih efektif dan efisien (Eduardo Simorangkir : 2016). Smart city sebagai suatu tempat dimana jaringan dan layanan tradisional dibuat lebih fleksible, efisien dan berkelanjutan dengan pengunaan teknologi informasi, digital dan telekomunikasi untuk memperbaiki operasi agar dapat memberi manfaat untuk penduduk (Mohanty : 2016).

Smart governance adalah salah satu kunci dari smart city (Alvaro Palomo-Navarro et.al : 2017). Salah satu yang cukup potensial dalam tata kelola pemerintah adalah keuangan. Sehingga dapat ditarik kesimpulan bahwa akuntansi yang merupakan bagian dari sistem informasi itu sendiri mempunyai peranan penting dalam mewujudkan smart city.

Tata Kelola teknologi informasi telah ditetapkan dalam Peraturan Menteri Komunikasi dan Informatika yaitu PerMenKominfo No. 41 Tahun 2007 tentang Panduan Umum Tata Kelola Teknologi Informasi Nasional yang bertujuan untuk mewujudkan tata kelola pemerintahan yang baik dan bertanggung jawab (good governance) melalui penerapan prinsip - prinsip akuntabilitas, transparansi dan supremasi hukum serta melibatkan partisipasi masyarakat dalam setiap proses kebijakan publik. Dikarenakan peraturan tersebut, seluruh instansi pemerintah baik pada level pusat maupun daerah wajib mempunyai Tata Kelola sebagai tolak ukur pengelolaan dan pelayanan teknologi informasi (Wardani, Murahartawaty, dan Ramadani : 2016)

Di Indonesia, Kota-kota besar seperti Surabaya, Jakarta, dan Bandung, cukup lama mengadopsi konsep smart city. Kota-kota tersebut kini menjadi panutan bagi kota dan kabupaten lain seperti Batam, Banyuwangi, Bojonegoro, dan Bali dalam penerapannya (Bintoro Agung : 2017).

Jakarta sebagai ibukota yang menaungi hampir 10 juta jiwa penduduknya, Jakarta dituntut untuk terus menjadi kota cerdas, dan siap 
disejajarkan dengan smart city lainnya di dunia, seperti Hong Kong, London, Berlin, dan New York. Jakarta Smart City adalah penerapan konsep kota cerdas yang mengoptimalkan pemanfaatan Teknologi Informasi dan Komunikasi (ICT) untuk mengetahui, memahami, dan mengendalikan berbagai sumber daya di dalam kota dengan lebih efektif-efisien demi memaksimalkan pelayanan publik, memberikan solusi penyelesaian masalah, dan mendukung pembangunan berkelanjutan (Nextdev : 2016).

Dillard (2008) mengusulkan bahwa sistem informasi akuntansi dapat di lihat dari 3 perspektif atau tingkatan, yaitu :

1. Teknologi dan teknik (apa sistemnya?)

2. Praktik (bagaimana sistem digunakan?)

3. Kontek sosial politik (dimana lingkungan sistem dioperasionalkan dan berkelanjutan?)

Berdasarkan penjelasan pada latar belakang, identifikasi masalah pada penelitian ini adalah penulis ingin mengetahui :

1. Bagaimana teknologi dan teknik sistem informasi akuntansi pada smart city di Jakarta?

2. Bagaimana praktik sistem informasi akuntansi untuk mewujudkan smart city di Jakarta?

3. Bagaimana kontek sosial politik berkaitan dengan operasi dan keberlanjutan sistem informasi akuntansi pada smart city di Jakarta?

\section{DASAR TEORI}

\section{A. Sistem Informasi Akuntansi}

Sistem informasi akuntansi di desain untuk mengumpulkan dan menyimpan data, kemudian data ini diberikan untuk para mengambil keputusan sebagai informasi yang relevan dan reliabel (Hank $\mathrm{C}$ Alewine, et al.: 2016). Sistem informasi akuntansi umumnya merupakan metode berbasis computer yang melacak aktivitas akuntansi dengan mengunakan teknologi informasi. Sistem informasi akuntansi bertanggungjawab atas pengumpulan, penyimpanan serta pengolahan data keuangan dan akuntansi yang digunakan untuk pengambilan keputusan manajemen internal (Fernando Belfo dan Antonio Trigo, 2013).

\section{B. Konsep Smart City}

Konsep "smart city" telah dikenalkan pada tahun 1994 (Dameri \& Corchia, 2013 dalam Ahvenniemi et al., 2016) dan sejak 2010, setelah adanya proyek smart city dan dukungan dari EU, sejumlah publikasi berkaitan dengan topik tersebut meningkat (Jucevicius, patasiene \& Patasius, 2014). Ahvenniemi, et al. (2017) merangkum terdapat dua hal utama berkaitan dengan diskusi smart city saat ini yaitu 1) pendekatan berorientasi ICT (information and communication technologies) dan 2) pendekatan berorientasi pada manusia.

Kota menjadi smart ketika investasi modal manusia dan sosial, teknologi informasi dan komunikasi mendorong pertumbuhan ekonomi berkelanjutan dan kualitas hidup yang tinggi, pengelolaan sumberdaya alam yang baik melalui partisipasif pemerintah (Carangliu, 2011). Adapun menurut Mohanty (2016), smart city adalah sebuah tempat dimana jaringan dan layanan tradisional dibuat lebih flesibel, efisien, dan berkelanjutan dengan menggunakan informasi, teknologi digital dan telekomunikasi, untuk memperbaiki operasinya untuk kepentingan penduduk. Smart city adalah greener, safer, faster, dan friendlier.

Smart city menggunakan ICT (information and communication technologies) untuk mengatur secara lebih efektif sumberdaya dan layanan yang ditawarkan sebuah kota dan membuat mereka lebih mudah didekati oleh semua stakeholder-nya seperti penduduk kota, perusahaan dan administrasi umum (Aguilera, 2016). Adapun sistem yang digunakan adalah sistem Internet of Things (IoT) Berbasis teknologi Cloud Computing.

Internet of Things (IoT) adalah jenis jaringan dari beberapa benda fisik atau benda yang disatukan oleh software, elektronik, sensor, konektifitas yang memungkinkan mencapai nilai dan layanan lebih besar dengan bertukar data dengan produsen, operator, dan beberapa perangkat lain yang terhubung (Christos Stergiou et al., 2016). Internet of Things (IoT) juga merupakan revolusi teknologi baru yang bercitacita untuk menghubungkan semua benda fisik sehari-hari ke Internet, membuat jaringan global yang sangat besar dengan hal-hal unik yang dapat berbagi informasi antara satu sama lain dan 
menyelesaikan tugas terjadwal, membawa manfaat signifikan bagi pengguna smart city (Vasileoios A. Memos, et al.:2017).

\section{Good Governance}

Good governance merupakan tata kelola yang baik pada suatu usaha yang dilandasi oleh etika profesional dalam berusaha/berkarya. Pemahaman good governance merupakan wujud penerimaan akan pentingnya suatu perangkat peraturan atau tata kelola yang baik untuk mengatur hubungan, fungsi dan kepentingan berbagai pihak dalam urusan bisnis maupun pelayanan public (SriTrisnaningsih : 2007)

\section{Sistem Informasi Akuntansi Untuk Smart City}

Smart city bertujuan untuk memperbaiki pelayanan kepada penduduk kota memberi pengaruh baik secara ekonomi (lebih efisien) dan sosial (keefektifan kepada kebutuhan dan keinginan para stakeholder). Pencapaian tujuantujuan ini tergantung tidak hanya pada data yang disediakan oleh pemerintah, pemegang wewenang dan pengambil keputusan, tapi juga pada data yang disediakan oleh penduduk, dan mereka dapat dilihat sebagai intelligent sensors (M.F. Goodchild, 2007)

Kaitan sistem informasi akuntansi pada smart city, Brown et al. (2005) menyatakan kebutuhan untuk memperluas cakupan sistem informasi akuntansi dalam mendukung keputusan bukan hanya mencakup ekonomi berkelanjutan, tapi juga tanggung jawab sosial dan lingkungan.

\section{E. Sosial Politik dan Smart City}

Istilah sosial politik terdiri berasal dari dua kata, yaitu sosiologi dan politik. Sosiologi adalah ilmu yang mempelajari masyarakat, kelompok kelompok sosial, dan tingkah laku individu baik individual maupun kolektif dalam konteks sosial. Politik adalah ilmu yang mempelajari kekuasaan sebagai konsep inti. Dengan demikian,dapat disimpulkan bahwa sosiologi politik adalah ilmu tentang kekuasaan, pemerintahan, otoritas, dan komando di dalam semua masyarakat manusia, tidak hanya di dalam masyarakat nasional.

Sosial dan politik mempunyai hubungan dan ketekaitan yang sangat erat. Seperti yang kita ketahui, bahwa dunia politik pasti berkenaan dengan dunia sosial masyarakat. Masyarakat menjadi penghubung antara sosial dan politik itu sendiri. Di dalam kegiatan politik, kita tidak bisa lepas dari partisipasi masyarakat karena masyarakatlah yang menjadi pelaku politik tersebut. Begitu juga sebaliknya, dalam kehidupan sosial kita tidak bisa lepas dari unsur unsur politik (sosialpolitik.filsafat.ugm.ac.id: 2017).

Sosial politik mempunyai kaitan dengan penerapan smart city, karena smart city sendiri mencakup berbagai aspek dan akan berkaitan dengan kebutuhan dan sendi-sendi yang ada di masyarakat. Kota yang baik, tentunya dimulai dari kualitas yang ada. Misalnya, untuk sektor ekonomi, sosial, sejarah, politik.

\section{METODOLOGI PENELITIAN}

Pada penelitian ini yaitu metode kualitatif deskriptif, dimana menggunakan informasi dari literature, website pemerintahan kota Jakarta yaitu http://smartcity.jakarta.go.id/, http://www.jakarta.go.id/home/,

http://pajakonline.jakarta.go.id, wawancara serta artikel dari internet. Artikel jurnal utamanya dari ScienceDirect, pencarian dilakukan dengan menggunakan kata kunci ("Accounting Information System for Smart City", "Smart City", "Accounting Information System") dan artikel-artikel relevan yang telah diseleksi. Artikel yang dipilih ditinjau untuk mengidentifikasi kerangka kerja dan faktor kunci sistem informasi akuntansi untuk smart city.

\section{HASIL DAN PEMBAHASAN}

\section{A. Teknologi dan Teknik Sistem Informasi Akuntansi Pada Smart City di Jakarta}

Berdasarkan data dari http://smartcity.jakarta.go.id, Smart city Jakarta mengadopsi penggunaan Internet of Things (IoT) dan berbagai teknologi informasi komunikasi lain untuk membantu jalannya pemerintahan. Bagi beberapa kota pintar termasuk Jakarta, teknologi digunakan utamanya untuk mengumpulkan data dan menganalisisnya sebagai dasar penentuan kebijakan.

Jakarta sebagai ibu kota negara, juga sedang mengembangkan diri menjadi kota pintar. Unit Pengelola Jakarta Smart City memastikan 
kota ini menjadi rumah bagi startup dan perusahaan berbasis teknologi yang ingin berperan untuk membangun smart city. Sebagai langkah menuju kota pintar, Jakarta memanfaatkan teknologi untuk memahami kebutuhan warga dan meningkatkan pelayanan publik. Salah satu bentuk pengembangan smart city dalam bidang keuangan adalah kampanye "Gerakan Nasional Non Tunai" (GNNT) yang dilakukan Bank Indonesia (BI) dan Pemerintah. GNNT resmi dicanangkan Bank Indonesia sejak 14 Agustus 2014 dengan penandatanganan Nota Kesepahaman antara Bank Indonesia dengan Kemenko Bidang Perekonomian, Kementerian Keuangan dan Pemerintah Daerah sebagai komitmen mendukung GNNT. Dengan GNNT diharapkan meningkatkan kesadaran masyarakat, pelaku bisnis dan lembaga pemerintah untuk menggunakan sarana pembayaran non tunai (Less Cash Society/LCS) dalam transaksi keuangan sehingga menjadi lebih mudah, aman dan efisien.

Pemprov DKI Jakarta dalam hal ini memberlakukan sistem open data. Dengan demikian, para pemangku kepentingan, baik pemerintah, swasta, maupun masyarakat, bisa mengakses data yang dimiliki Pemprov untuk menciptakan solusi-solusi cerdas. Di laman Jakarta.go.id, misalnya, warga bisa langsung mengunduh segala informasi tentang Jakarta. Mulai dari data keuangan daerah dan data kependudukan yang sifatnya umum, hingga data spesifik seperti data trayek umum bus besar, data titik rawan kemacetan, atau data rata-rata tamu asing menginap di Jakarta

\section{Gambar 4.1 Prinsip Smart City di Jakarta}

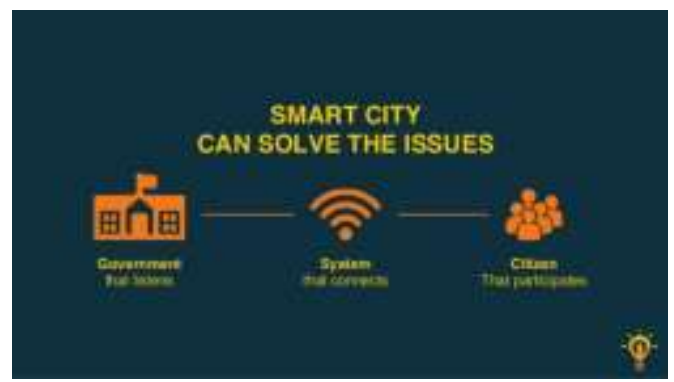

Sumber : smartcity.jakarta.go.id

Membangun sistem informasi akuntansi untuk smart city masih belum menjadi fokus utama pemerintah provinsi DKI Jakarta. Berdasarkan APBD 2017, ditemukan bahwa komposisi belanja dan pembiayaan terbesar adalah $27,51 \%$ untuk pendidikan sebesar 17,49 Trilyun, $18,15 \%$ untuk penanggulangan kemacetan lalu lintas sebesar 12,73 Trilyun, 13\% kesehatan sebesar 8,27 Trilyun, 7,33\% untuk rusun dan fasilitas pendukung sebesar 4,66 Tirlyun, 4,91\% untuk penanggulangan banjir sebesar 3,12 Trilyun dan 4,69\% untuk penanganan sampah dan kebersihan 2,98 Trilyun. Pembiayaan diatas sudah mencapai $75,59 \%$ dari APBD. APBD mempengaruhi arah pengembangan smart city lebih dikembangan ke bagian-bagian tersebut diatas.

\section{B. Praktik Sistem Informasi Akuntansi Untuk Mewujudkan Smart City Di Jakarta}

Internet of Things yang juga dikenal dengan IoT merupakan sebuah konsep yang masih terus berkembang. IoT menggunakan pemrograman untuk menghasilkan interaksi antar mesin tanpa campur tangan manusia. Interaksi tersebut memanfaatkan konektivitas internet yang tersambung secara terus-menerus. Komunikasi antar mesin atau benda yang menggunakan teknologi IoT dapat berupa pertukaran data atau pengendalian jarak jauh. Teknologi tersebut juga menjadi pendukung utama pembangunan kota pintar atau smart city.

Berdasarkan data dari http://smartcity.jakarta.go.id, Jakarta smart city sebagai unit pengelola kota pintar di DKI Jakarta telah mengaplikasikan teknologi tersebut di berbagai bidang antara lain CCTV Online, Pelacak Lokasi Truk Sampah, Pelacak Lokasi Bus Transjakarta, Teknologi CityTouch, dan Automatic Water Level Recorder. IoT belum banyak menyentuh secara spesifik pada bidang keuangan, namun disana tertulis bahwa IoT ini akan terus merambah ke bidang-bidang lain.

Berdasarkan penelusuran ke http://www.jakarta.go.id/home/ dan kemudian dilanjutkan http://pajakonline.jakarta.go.id, ditemukan bahwa untuk mewujudkan smart city, Jakarta menerapkan sistem pajak online. Sistem ini selain mempermudah masyarakat, juga mewujudkan sistem perpajakan dan sistem keuangan yang transparan.

Jenis pajak yang tersedia untuk layanan on-line DKI Jakarta adalah pajak kendaraan 
bermotor, bea balik nama kendaraan bermotor, pajak bahan bakar kendaraan bermotor, pajak air dan tanah, pajak hotel, pajak restoran, pajak hiburan, pajak reklame, pajak penerangan jalan, pajak parkir, pajak bea perolehan hak atas tanah dan bangunan, pajak rokok, pajak bumi dan bangunan, serta pajak air permukaan. Adapun untuk pajak penghasilan $\mathrm{PPh} 21$ langsung ditangani oleh pemerintahan Negara dan dapat dilakukan secara online.

\section{Gambar 4.1 Pembayar Pajak Secara Online}

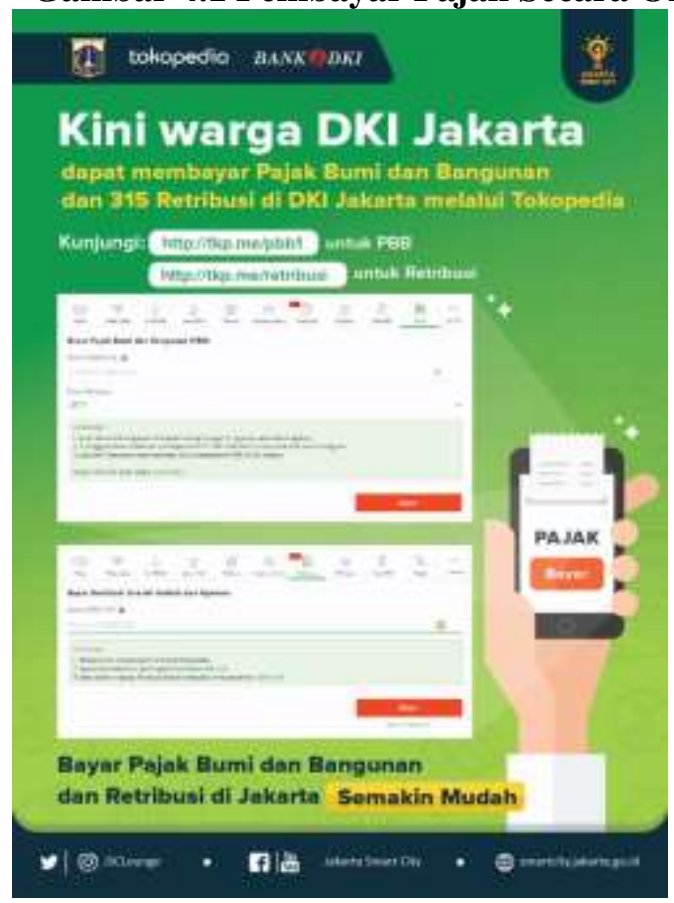

Sumber : smartcity.jakarta.go.id

Salah satu usaha Pemprov DKI Jakarta untuk mengoptimalisasi penerimaan pajak pada tahun 2017 adalah dengan mewajibkan penggunaan alat Electronic Point of Sales. Alat tersebut wajib digunakan di tempat usaha seperti restoran, rumah makan, dan tempat hiburan.

Electronic Point of Sales memiliki sistem yang terkomputerisasi sehingga dapat memproses transaksi keuangan layaknya mesin kasir. Selain itu, alat tersebut dilengkapi dengan sistem manajemen yang terintegrasi dengan perhitungan pajak. Electronic Point of Sales mencatat atau merekam nominal pajak yang wajib dikeluarkan oleh pengusaha secara real time dan terhubung secara online dengan Dinas Pelayanan Pajak Pemprov DKI Jakarta. Konsumen juga dapat mengetahui pajak yang dibebankan secara langsung dari nota pembayaran. Apabila aliran listrik terhenti, alat tersebut dapat menggunakan daya dari baterai. Gangguan pada perangkat Electronic Point of Sales dapat dideteksi oleh Dinas Pelayanan Pajak Pemprov DKI Jakarta, termasuk jika pihak pemilik usaha melakukan kecurangan seperti memutus atau menonaktifkan jaringan.

Perekaman dan perhitungan pajak secara otomatis melalui Electronic Point of Sales memungkinkan berkurangnya tatap muka antara pemilik usaha sebagai wajib pajak dengan petugas pajak. Dengan demikian, kecurangan perhitungan pajak dapat dihindari. Dengan penerapan alat Electronic Point of Sales.

Dari penjabaran diatas dapat dilihat bahwa pada tahap-tahap tertentu pemerintah provinsi DKI telah melakukan langkah - langkah kongkrit mewujudkan smart city dari pengembangan sistem informasi akuntansi agar mampu memberi pelayanan lebih baik bagi penduduk Jakarta.

\section{Konsep dan Praktik Kartu Jakarta One}

Pada bulan juni 2016, Gurbernur Basuki Tjahaja Purnama resmi meluncurkan Kartu Jakarta One. Program ini bagian dari sistem informasi akuntansi untuk mewujudkan smart city, dimana merupakan hasil kerjasama antara Bank DKI dengan Bank Indonesia. Berbagai fasilitas dan layanan juga telah dibangun oleh Pemprov DKI Jakarta dalam rangka mewujudkan Jakarta sebagai smart city

Kartu Jakarta One berfungsi untuk meningkatkan pelayanan publik dan keterbukaan informasi.. Kartu Jakarta One hadir dengan bentuk elektronifikasi informasi dan transaksi sistem pembayaran. Sehingga warga Jakarta bisa melakukan transaksi untuk berbagai kebutuhan hanya dengan satu kartu tanpa perlu membayar uang tunai.

Kartu ini diharapkan bisa digunakan mulai dari pembayaran bus Transjakarta, angkutan umum masa depan (MRT, LRT), RSUD, rusun, pajak, retribusi, parkir meter, asuransi kesehatan BPJS hingga penyaluran kredit kepada pelaku UKM (usaha kecil menengah) dan museum/tempat wisata, bahkan menyalurkan bantuan subsidi untuk masyarakat miskin dan belanja ritel/took. Dengan adanya kartu ini transaksi non tunai dilakukan dan bank 
membuka informasi tersebut, maka pengawasan keuangan dan aset daerah dapat dipantau dengan mudah. Aliran dana tersebut juga tak dapat dimanipulasi sehingga pejabat tak akan berani untuk korupsi.

Dari hasil wawancara dengan 3 custumer services Bank DKI pada tanggal 19 Desember 2017, untuk Kartu Jakarta One yang di usung Gubernur Basuki Tjahaja Purnama masih sebatas untuk pembayaran Busway dan masuk tempat wisata Rangunan. Berdasarkan hasil wawancara dan di dukung dengan penelusuran di http://smartcity.jakarta.go.id serta pemberitan di media, dapat ditarik kesimpulan bahwa implikasi program kartu one masih masih jauh dari konsep yang telah dibuat.

\section{Kontek Sosial Politik Berkaitan Dengan Operasi Dan Keberlanjutan Sistem Informasi Akuntansi Pada Smart City Di Jakarta}

Kondisi sosial politik mempengaruhi perkembangan operasi dan keberlanjutan sistem informasi akuntansi sebagai bagian tata kelola keuangan untuk mewujudkan smart city di DKI Jakarta.

Pergantian dari Gubernur Basuki Tjahaja Purnama ke Gubernur Anies Baswedan yang resmi dilantik pada Oktober 2017 mempengaruhi keberlanjutan program yang sudah di mulai saat kepemimpinan Basuki Tjahaja Purnama, salah satunya adalah program Kartu Jakarta One. Dari penelusuran ditemukan melalui rapat yang digelar bersama Otoritas Jasa Keuangan (OJK), salah satu poin yang dibahas adalah Kartu Jakarta One (www.swamedium.com : 31 Oktober 2017). Walaupun, pembahasan soal Kartu Jakarta One masih berupa konsep dan belum sampai pada tahap pemaparan yang lebih terperinci.

\section{KESIMPULAN}

Berdasarkan hasil penelitian diatas menghasilkan beberapa kesimpulan, adalah sebagai berikut:

1. Pengembangan sistem informasi akuntansi masih belum menjadi fokus utama Pemprov DKI Jakarta. Pembiayaan terbesar dari APBD adalah pendidikan, penanggulangan kemacetan lalu lintas, kesehatan, rusun dan fasilitas pendukung, penanggulangan banjir serta penanganan sampah Pembiayaan diatas sudah mencapai 75,59\% dari APBD. APBD mempengaruhi arah pengembangan smart city.

2. Pada tahap-tahap tertentu pemerintah provinsi DKI telah melakukan langkahangkah kongkrit mewujudkan smart city dari pengembangan sistem informasi akuntansi agar mampu memberi pelayanan lebih baik bagi penduduk Jakarta.

3. Konsep Kartu Jakarta One sebagai salah satu dari program smart city diharapkan transaksi non tunai dilakukan dan bank membuka informasi tersebut, maka pengawasan keuangan dan aset daerah dapat dipantau dengan mudah. Aliran dana tersebut juga tak dapat dimanipulasi sehingga pejabat tak akan berani untuk korupsi, pada saat ini praktiknya masih sebatas untuk melakukan pembayaran busway dan masuk ke wisata Rangunan.

4. Melihat perkembangan tata kota di Jakarta, pada tataran konsep dapat dikatakan sangat cepat, namun pada proses implementasi tidak secepat wacana yang bergulir terus menerus.

\section{DAFTAR PUSTAKA}

A. Caragliu, Ch. Del Bo, P. Nijkamp, Smart cities in Europe, (2011). In J. Coelho, N. Cacho, F. Lopes, E. Loiola, T. Tayrony, T. Andrade, M. Mendon ${ }_{s}$ ca, M. Oliveira, D. Estaregue, B. Moura, ROTA: A Smart City Platform to Improve Public Safety. 2016

Aguilera Unai, Oscar Pena, Orcar Belmonte, Diego Lopez-De-Ipina. 2016. CitizenCentric Data Services for Smarter Cities. Future Generation Computer Systems. Published by Elsevier Inc.

Ahvenniemi Hannele, Aopo Huovila, Isabel Pinto-Seppa, Mimmu Airaksinen. 2016. What are Dufferences Between Sustainable And Smart Cities. Published by Elsevier Inc. 
Alvaro Palomo-Navarro, and Julio Navío-Marco. 2017. Smart city networks' governance: The Spanish smart city network case study. Telecommunications Policy.p: 1-9.

António Trigo, Fernando Belfo a,b, Raquel Pérez Estébanezc. 2014. Accounting Information Systems: The Challenge of the Real-Time Reporting. Procedia Technology 16 . p:118 127

Aysel Güney. 2014. Role of technology in accounting and e-accounting. Procedia Social and Behavioral Sciences 152. $\mathrm{p}: 852-855$

Aysel Güney. 2014. Role of technology in accounting and e-accounting. Procedia Social and Behavioral Sciences 152. p:852-855

Bintoro Agung : 2017

https://www.cnnindonesia.com/teknologi/ 20171102220249-185-253130/langkahdan-kendala-adopsi-smart-city-diindonesia/

Brown. D, Dillard. J, Marshall. S. 2005. Incorporating Natural System as Part of Accounting's Public Interest Responsibility. Jurnal Information System 19 (2).p: 79-104

Christos Stergiou, Kostas E. Psannis, Byung-Gyu Kim, Brij Gupta. 2016. Secure integration of IoT and Cloud Computing, Future Generation Computer Systems. http://dx.doi.org/10.1016/j.future.2016.11. $\underline{031}$

Claudiu Brandas, Ovidiu Megana, Otniel Didragaa. 2015. Global perspectives on accounting information systems: mobile and cloud approach. Procedia Economics and Finance 20. p.88-93

Dillard, J., 2008. Responding to expanding accountability regimes by re-presenting organizational context. Int. J. Account. Inf. Syst. 9, 21-42

Eduardo Simorangkir. 2016 https://finance.detik.com/berita-ekonomibisnis/3224822/ini-konsep-kota-cerdasmenurut-pencetus-smart-city

Fernando Belfo, António Trigo. 2013. Accounting Information Systems: Tradition and Future Direction. Procedia Technology 9. p:536 $-546$

Hank C Alewine, Christopher D. Allport, WeiCheng Milton Shen. 2016. How Measurement Framing and Accounting Information System Evaluation Mode Influence Environmental Performance Judgments. International Journal of Accounting Information System 23. P:2844

http://data.jakarta.go.id/base/dokumen/BIB2017.pdf

http://jakarta.bisnis.com/read/20171116/77/7096 87/sebulan-jadi-gubernur-anies

http://pajakonline.jakarta.go.id

http://smartcity.jakarta.go.id/blog/176/optimalisa si-penerimaan-pajak-dengan-electronicpoint-of-sales

http://smartcity.jakarta.go.id/blog/61/kartujakarta-one-satu-kartu-untuk-semua

http://smartcity.jakarta.go.id/index.php/blog/177/ pemanfaatan-teknologi-internet-of-thingsiot-di-jakarta-smart-city

http://smartcity.jakarta.go.id/index.php/blog/239/ jakarta-dan-proyek-smart-city-diindonesia

http://www.jakarta.go.id/home/

http://www.swamedium.com/2017/10/31/rapatdengan-ojk-pemprov-dki-lanjutkanprogram-kartu-jakarta-one/

https://komite.id/2017/04/18/program-smartcity-dki-jakarta-libatkan-teknologivisionary-ai-kelas-dunia/ 
https://kreditgogo.com/artikel/Informasi-

Umum/Jakarta-One-Satu-Kartu-untuk-

Semua-Kebutuhan.html

https://sosialpolitik.filsafat.ugm.ac.id/bagaimana -kondisi-sosial-politik-di-indonesia/

https://swa.co.id/swa/trends/technology/memban gun-jakarta-sebagai-kota-cerdas

Jucevicius.R, Patasiene.I, and Patasius.M. 2014. Digital Deminsion of Smart City: Critical Analysis. Procedia - Sosial and Behavioral Sciences, 156. 146-150.

M.F. Goodchild. 2007. Citizens as sensors: the world of volunteered geography. GeoJournal 69 (4) 211-221.

Maros Lacinak, Jozef Ristvej. 2017. Smart city, Safety and Security. Procedia Engineering 192,. p:522 - 527.

Maziyar Ghasemi, Vahid Shafeiepour, Mohammad Aslani, Elham Barvayeh. 2011. The impact of Information Technology (IT) on modern accounting systems. Procedia - Social and Behavioral Sciences 28. p:112- 116 .

Mohanty. 2016. Everything You Wanted to Know About Smart Cities. DOI: 10.1109/MCE.2016.2556879

Nextdev : 2016.

http://thenextdev.id/new/update/index.php /2016/02/25/apa-itu-jakarta-smart-city/

Oris Krisanto Sulaiman, Adi Widarma. 2017. Sistem internet Of Things (Iot) Berbasis cloud Computing Dalam Campus Area Network. www.researchgate.net

Sosial Politik UGM. 2017. https://sosialpolitik.filsafat.ugm.ac.id/bag aimana-kondisi-sosial-politik-diindonesia/

Vasileios A. Memos, Kostas E. Psannis, Yutaka Ishibashi, Byung-Gyu Kim, and B.B Gupta. 2017. An Efficient
Algorithm for Media-based Surveillance System (EAMSuS) in IoT smart city framework. Published by Elsevier Inc

Wardani, Murahartawaty, \& Ramadani.

Perancangan Tata Kelola Layanan Teknologi Informasi Menggunakan ITIL versi 3 Domain Service Transition Dan Service Operation Di Pemerintah Kota Bandung. Journal of Information Systems Engineering and Business Intelligence, 2016, 2 (2), 81-87 